\title{
BENDING PROPERTIES AND ASH CONTENT OF FETAL CRANIAL BONE*
}

\author{
Timothy J. Kriewall + , Gregg K. McPherson $\ddagger$ and Alan Ch. Tsar \\ University of Michigan, Ann Arbor, MI 48109, U.S.A.
}

\begin{abstract}
Forty-five specimens of fetal cranial bone ranging in estimated gestational age from $25-40$ weeks were tested in three-point bending. Five specimens of a six-year-old calvarium were tested for comparative purposes. The elastic modulus of each specimen was derived from the bending stiffness and geometrical property data. Following mechanical testing, each specimen was oven-dried and ashed to a constant weight. Ash content was determined as the ratio of ash weight to dry specimen weight. The results indicate that the ash content of fetal cranial bone increases significantly (from $50 \%$ to $68 \%$ ) with increasing gestational age. (The elastic modulus of fetal cranial bone significantly increases with increasing ash content.) However, the ash content of the term fetal cranial bone or the six-year-old cranial bone is not significantly different from that found in the adult. These results are discussed in relation to a structural hypothesis for increasing cranial bone stiffncss with incrcasing maturity.
\end{abstract}

\section{INTRODUCTION}

A number of investigators have attempted to correlate the mechanical properties of bone with their histological properties (Currey, 1969; Dalen et al., 1976; Wright and Hayes, 1976; Wall et al., 1972). These investigations have been primarily directed toward a better understanding of fracture strength of the long bones, particularly in osteoporotic patients.

To date, no studies have been performed to relate the mechanical and histological properties of fetal bone. Yet, the mechanical properties of fetal bone can have a significant effect on the long term well-being of the fetus. During the process of labor, the skull bones of the fetus are deformed due to the pressure exerted by the amniotic fluid and soft tissues of the maternal birth passages. Such deformations are termed molding and are a normal part of every labor. Excessive molding, however, has been implicated in a spectrum of psychoneurologic disorders (Willerman, 1970; Glenting, 1970, Fianu, 1976). A better understanding of the biomechanics of the molding process requires a knowledge of not only the structure of the fetal head, but also the material properties of the various tissues.

\section{MATERIAL AND METHODS}

The fetal cranial bone used in this study was obtained from six subjects ranging in estimated ges-

* Received 3 January 1980; in revised form 1 July 1980.

$\dagger$ Address reprint requests to: Assistant Professor, Obstetrics and Gynecology and The Bioengineering Program, L2011 Women's Hospital, Box 07, The University of Michigan, Ann Arbor, MI 48109, U.S.A.

$\ddagger$ Bioengineering Program, University of Michigan, Ann Arbor, MI 48104, Present Address: 3M Company, Surgical Products Division, St. Paul, MN 55101, U.S.A.

§ Associate Professor, Human Nutrition Program, University of Michigan, Ann Arbor, MI 48109, U.S.A. tational age from 25 to 40 weeks. In addition, the calvarium of a six-year-old child was tested for comparative purposes. No material was utilized in this study which showed evidence of deterioration due to pathological conditions. Table 1 provides a summary of the biographical data for the test material.

Three-point bending tests were performed on 45 specimens obtained from the six fetal calvariums and 5 full-section specimens obtained from the six-year-old calvarium. The exact test procedures are explained in detail elsewhere (McPherson and Kriewall, 1980). Briefly, however, the test procedure was as follows: 1. A $25 \mathrm{~mm}$ square template was used to outline various segments on each bone (Fig. 1a). Using scissors, the outlined area of bone was excised (Fig. 1b). This section of bone was then positioned in a miter box with the bone fiber oriented so that finished bending specimens of $2 \mathrm{~mm} \times 25 \mathrm{~mm}$ would have preferred fiber orientations, primarily either parallel or perpendicular to the long axis of the bending specimen (Fig. 1c). Unlike an adult skull, fetal skull consists of a single layer of cortical bone. A radial pattern of trabeculae can be seen emanating outward from centers of ossitication, e.g., the parietal eminence (Fig. 1d).

2. The specimens were tested at room temperature under a constant drip of normal saline on an Instron Floor Model TT-C material testing machine.

3. Each specimen was centered on the bending supports of the test fixture with the convex surface upwards.

4. Each specimen was cycled three times to a midspan deflection of $0.25 \mathrm{~mm}$ at a crosshead speed in both loading and unloading of $0.55 \mathrm{~mm} / \mathrm{min}$.

5. Finally, each specimen was loaded to a midspan deflection of $1.5 \mathrm{~mm}$ at a crosshead speed of $0.5 \mathrm{~mm} /-$ min and then unloaded at the same speed.

The method of unit loads was utilized to account for the variability in specimen thickness. For a beam in 
Table 1. Biographical data for test material used in this investigation

\begin{tabular}{|c|c|c|c|c|c|c|}
\hline \multirow{2}{*}{$\begin{array}{c}\text { Calvarium } \\
\text { no. }\end{array}$} & \multirow{2}{*}{$\begin{array}{c}\text { Estimated } \\
\text { gestational age } \\
\text { (Weeks) }\end{array}$} & \multirow[b]{2}{*}{ Sex } & \multirow[b]{2}{*}{ Weight (g) } & \multicolumn{2}{|c|}{$\begin{array}{c}\text { Bone } \\
\text { thickness (mm) }\end{array}$} & \multirow[b]{2}{*}{ Cause of death } \\
\hline & & & & mean & S.D. & \\
\hline 1 & $40 \pm 2$ & $\mathbf{M}$ & 3118 & 0.76 & 0.10 & Congenital heart failure \\
\hline 2 & $38 \pm 2$ & $\mathrm{~F}$ & 2800 & 0.71 & 0.15 & - \\
\hline 3 & $27 \pm 2$ & $\mathbf{M}$ & 970 & 0.63 & 0.10 & $\begin{array}{l}\text { Insufficient respiratory } \\
\text { effort }\end{array}$ \\
\hline 4 & $25 \pm 2$ & $\mathbf{M}$ & 650 & 0.41 & 0.10 & Prematurity \\
\hline 5 & Not tested due & to bon & deterioration & - & - & \\
\hline 6 & $28 \pm 2$ & M & 1025 & 0.64 & 0.05 & $\begin{array}{l}\text { Systemic candidiasis, } \\
\text { bronchopulmonary dysplasia }\end{array}$ \\
\hline 7 & $40 \pm 2$ & $\mathbf{M}$ & 3640 & 0.86 & 0.08 & Meconium aspiration \\
\hline 8 & 6-year-old & $\mathbf{M}$ & 1660 & 3.33 & 0.28 & $\begin{array}{l}\text { Acute bronchopneumonia } \\
\text { (hydrocephalic) }\end{array}$ \\
\hline
\end{tabular}

pure bending, the load deflection equation can be expressed as:

$$
y=\int_{0}^{l} \frac{M m}{E I} \mathrm{~d} x
$$

where :

$$
\begin{aligned}
y= & \text { deflection at the desired location } \\
l= & \text { span length } \\
M= & \text { bending moment for the applied load } \\
& \text { distribution } \\
m= & \text { bending moment created by a unit point load } \\
& \text { acting at the location where the deflection is to } \\
& \text { be found } \\
E= & \text { elastic modulus } \\
I= & \text { area moment of inertia } \\
x= & \text { position along the span. }
\end{aligned}
$$

For a simply-supported beam with a concentrated load at midspan and a constant modulus of elasticity, (1) can be rewritten as :

$$
\delta=\frac{P}{4 E}\left\{\int_{0}^{l / 2} \frac{x^{2}}{I} \mathrm{~d} x+\int_{l / 2}^{l} \frac{(l-x)^{2}}{I} \mathrm{~d} x\right\}
$$

where:

$$
\begin{aligned}
& \delta=\text { deflection at midspan } \\
& P=\text { applied load at midspan } \\
& x=\text { linear coordinate along the beam. }
\end{aligned}
$$

To solve (2) requires the knowledge of the inertia of each beam section. Since the specimens had a varying thickness (Fig. 2), the beam was divided into four sections of constant inertia. By so doing, (2) reduces to :

$$
\delta=\frac{P l^{3}}{768 E}\left\{\frac{1}{I_{1}}+\frac{7}{I_{2}}+\frac{7}{I_{3}}+\frac{1}{I_{4}}\right\}
$$

where:

$$
I_{i}=\text { inertia of the } i \text { th section. }
$$

The width and thickness of each specimen were measured with dial calipers to the nearest $0.01 \mathrm{~mm}$ at the end support points, the midpoint, and the points equidistant between the support points and midpoint, Thus, the moment of inertia for each of the four segments was computed by averaging the adjacent inertias. This was repeated for each bending specimen.

The accuracy of this method was compared with both an eight element model using finite element methods and an eight section model using the unit load method (McPherson and Kriewall, 1980). The same measurement techniques were followed except the specimen was discretized into eight elements instead of four. An analysis of two randomly selected specimens, one relatively thick and one relatively thin, indicated the results for the four-section model deviated from the other more complex models by a maximum of two percent. Hence the simpler four-element model was used in all subsequent calculations to evaluate the modulus of the material.

Following mechanical testing, each specimen was dried in an oven at $75^{\circ} \mathrm{C}$ for $96 \mathrm{hr}$. They were weighed at 48,72 , and $96 \mathrm{hr}$ to insure their weights were not diminishing and that the $96-\mathrm{hr}$ weight was indeed the dry weight. The specimens were then ashed in a platinum crucible at $550^{\circ} \mathrm{C}$. The lowest of three consecutive ash weights was assumed to be the true ash weight for that sample.

\section{RESULTS}

Table 2 summarizes the results of the testing for the fetal cranial tissue while Table 3 gives the results for the six-year-old. The elastic modulus of the fetal cranial bone specimens is plotted as a function of the ash percentage of dry weight in Fig. 3. A linear regression curve was fitted to the data with a resulting correlation coefficient equal to $0.56(P<0.005)$.

In addition, the ash percentage of dry weight was plotted as a function of estimated gestational age (Fig. 4). A linear regression analysis of these data resulted in a correlation coefficient equal to $0.82(P<0.05)$.

\section{DISCISSION}

Previous investigators (Currey, 1969; Mather, 1968) have shown that there is a positive correlation between the elastic modulus of adult cortical bone and the 


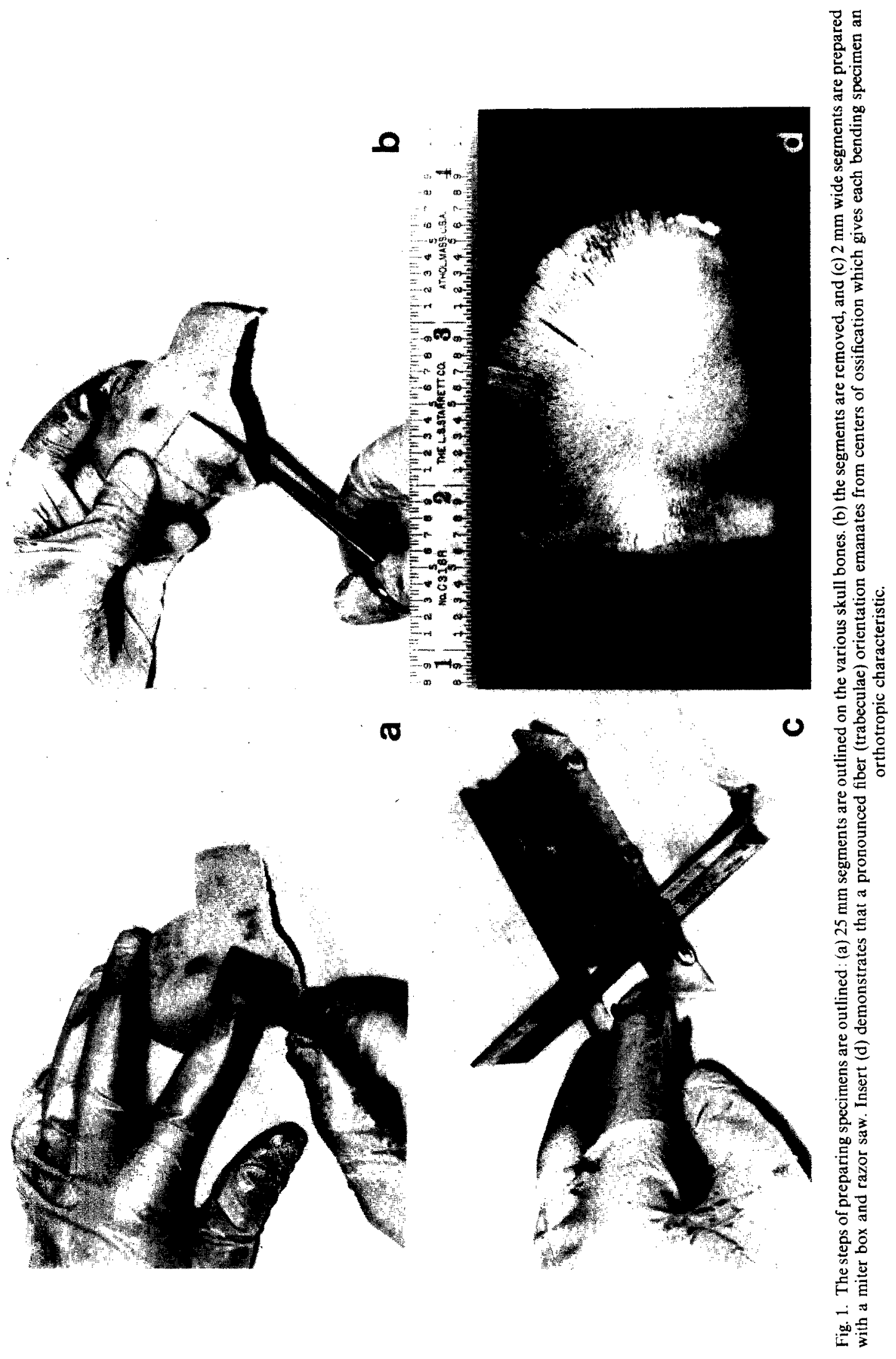




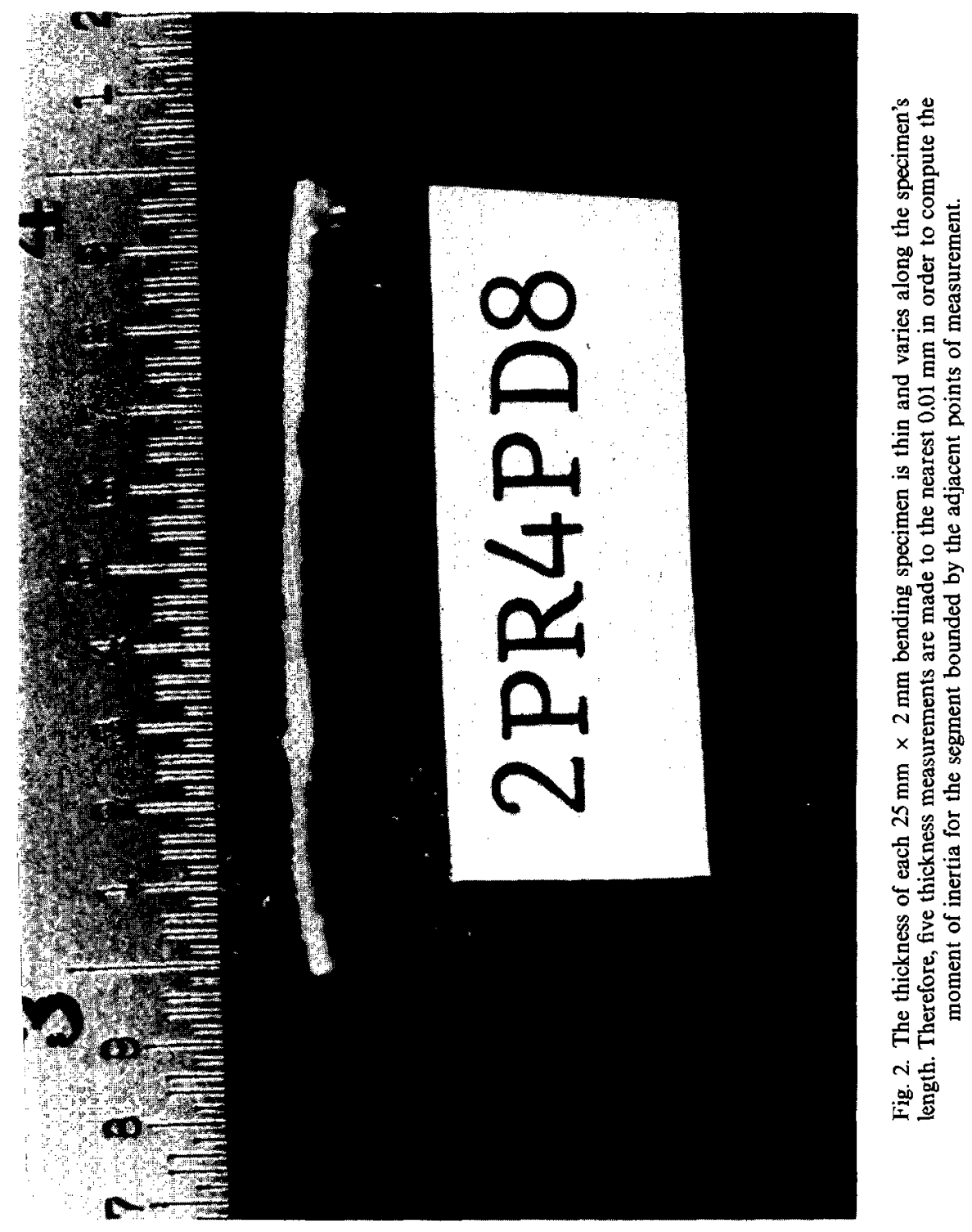


Bending properties and ash content of fetal cranial bone

Table 2. Elastic modulus and ash content of fetal cranial bone

\begin{tabular}{ccccccc}
\hline $\begin{array}{c}\text { Specimen } \\
\text { group* }\end{array}$ & $\begin{array}{c}\text { No. of } \\
\text { specimens }\end{array}$ & $\begin{array}{c}\text { Estimated } \\
\text { gestational age } \\
\text { (Weeks) }\end{array}$ & $\begin{array}{c}\text { Elastic modulus } \\
\text { Mean }\end{array}$ & $\begin{array}{c}\text { S.D } \\
\text { S.D }\end{array}$ & $\begin{array}{c}\text { Ash \% dry wt } \\
\text { Mean }\end{array}$ & S.D. \\
\hline 1PR \& FL & 5 & $40 \pm 2$ & 3627 & 1138 & 60.68 & 0.23 \\
2PR & 5 & $38 \pm 2$ & 4413 & 745 & 60.80 & 0.67 \\
3PL & 5 & $27 \pm 1$ & 1145 & 414 & 54.52 & 1.11 \\
4PR & 5 & $25 \pm 1$ & 1386 & 648 & 53.34 & 3.91 \\
6PR & 5 & $28 \pm 1$ & 3620 & 462 & 60.20 & 5.04 \\
7PR & 5 & $40 \pm 2$ & 3723 & 352 & 67.66 & 2.32 \\
7PL & 5 & $40 \pm 2$ & 3296 & 641 & 65.72 & 2.29 \\
7FL & 5 & $40 \pm 2$ & 3289 & 710 & 65.56 & 1.75 \\
7PR & 5 & $40 \pm 2$ & 2834 & 958 & 63.82 & 5.14 \\
\hline
\end{tabular}

* Long axis of all specimens oriented parallel to grain fiber. Abbreviations: PR, right parietal; PL, left parietal; FR, right frontal; FL. left frontal.

Table 3. Elastic modulus and ash content of six-year-old cranial bone

\begin{tabular}{ll}
\hline Bone & Left parietal \\
Specimen orientation & Parallel to sagittal suture \\
Number of specimens & 5 \\
Type of specimen & Full-section beam \\
Elastic modulus & \\
$\quad$ Mean & $7123 \mathrm{MPa}$ \\
S.D. & $586 \mathrm{MPa}$ \\
Ash $\%$ dry weight & \\
$\quad$ Mean & 66.36 \\
S.D & 0.79 \\
\hline
\end{tabular}

percentage of bone ash. The results of this investigation of fetal cranial bone support that conclusion (Fig. 3). It is of interest to note, however, that the range of values for ash content is significantly larger for fetal cranial bone $(50-68 \%)$ than those values quoted by Currey (1969) for adult cortical bone (63-68\%). This wide range of values for the ash content is indicative of the dynamic nature of the mineral deposition process during the gestational period. This conclusion is enhanced by the results shown in Fig. 4 which indicate that a positive correlation exists between ash content

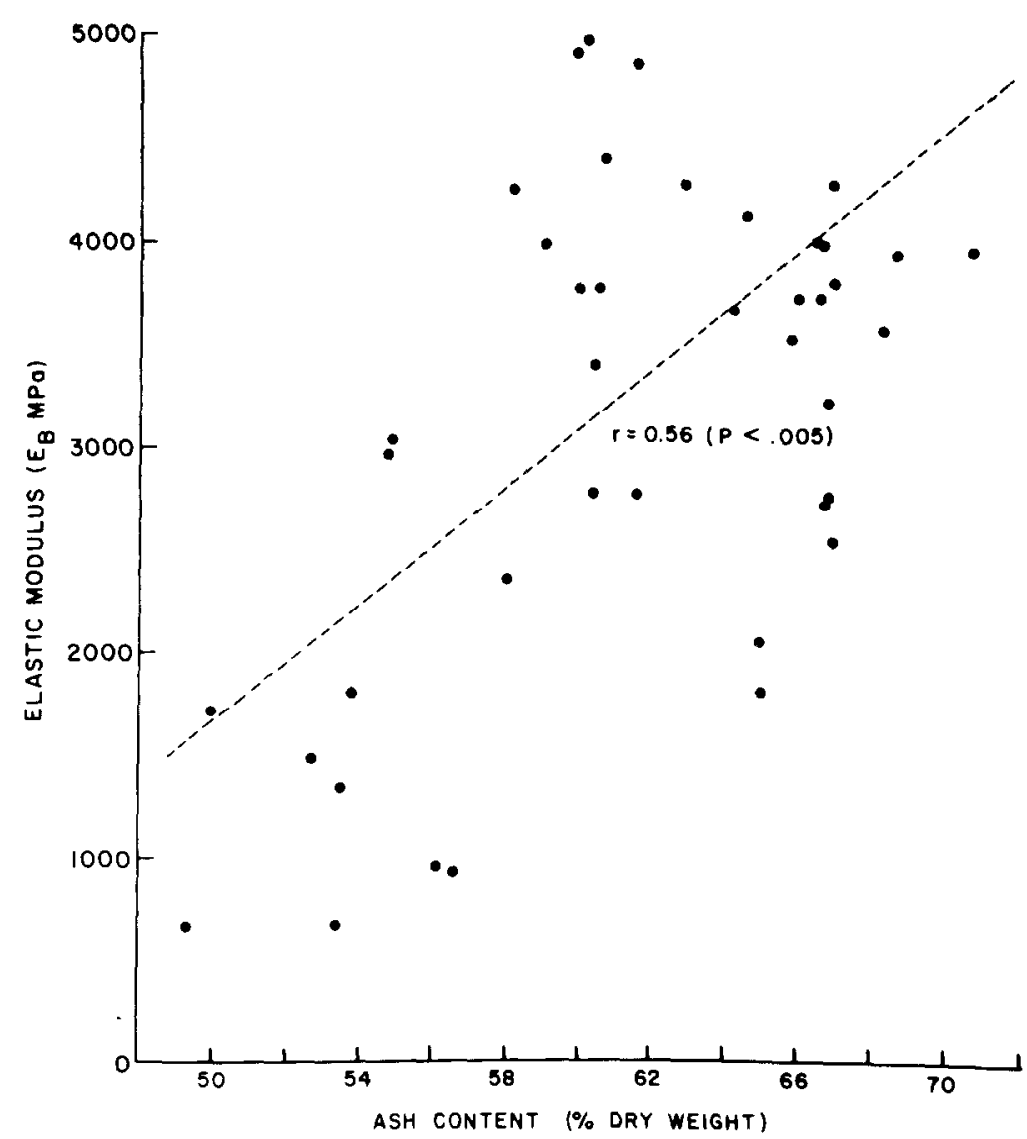

Fig. 3. The elastic modulus of fetal cranial bone as a function of ash content is plotted. The dotted line is the least-square fit for the average values. 


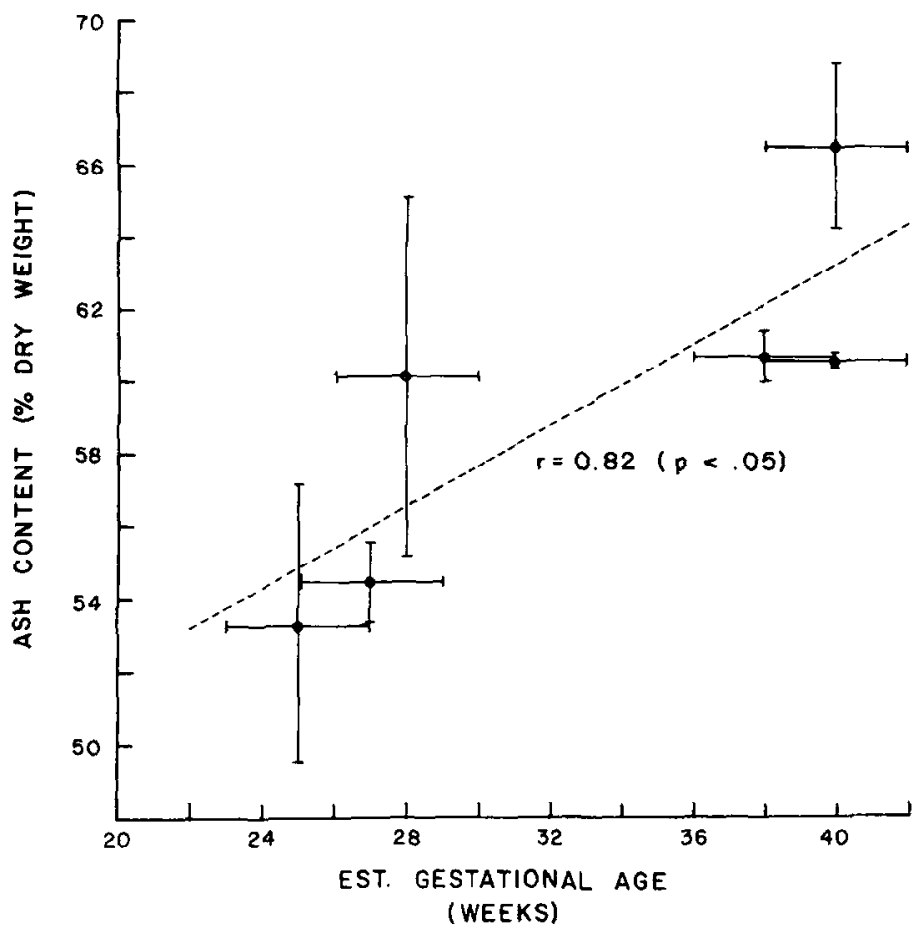

Fig. 4. The ash content of fetal cranial bone as a function of estimated gestational age is plotted. The vertical bars represent \pm 1 S.D. of the mean value of all specimens from each skull while the horizontal bars represent the range of estimated gestational age. The regression was performed on the average values.

and estimated gestational age.

By the time fetus has reached full term, the mineral content of the cranial bones is in the same range as that found in the adult. The comparative data from the sixyear-old (Table 2) tend to support this conclusion. While the ash content remains relatively constant from the time of birth to adulthood, the elastic modulus does not. Comparison of the values listed in Tables 1 and 2 indicate that the elastic modulus is significantly higher at 6 years of age than at birth. Hubbard (1971) tested full-section specimens of adult cranial bone in three-point bending. He reported a mean value for the elastic modulus of $9929 \mathrm{MPa}$, which is significantly higher than that found in the six-year-old (viz. $7123 \mathrm{MPa}$ ).

It has been previously hypothesized (McPherson and Kriewall, 1980) that this increase in elastic modulus with increasing maturity is largely a structural effect as opposed to a material effect. Cranial bone undergoes considerable structural differentiation from birth to adulthood with the primary change being the development of an intermediate layer of cancellous bone known as the diploe. The overall result of this differentiation is the creation of cranial bone structure very reminiscent of honeycomb sandwich structures known in the aerospace industry for their high stiffness-to-weight ratio. The fact that ash content does not increase significantly from birth to adulthood lends further support to the structural theory of increasing bone stiffness with increasing maturity.

\section{CONCLUSIONS}

The bending tests and ashing of specimens of fetal cranial bone have resulted in the following conclusions:

1. The ash content of fetal cranial bone increases with increasing gestational age.

2. The ash content of term fetal cranial bone is not significantly different from that found in the adult.

3. The elastic modulus of fetal cranial bone increases with increasing ash content.

4. The increasing stiffness of cranial bone from birth to adulthood is largely a result of structural differentiation as opposed to material changes.

Acknowledgements - This work was supported in part by grant HD11202 from the National Institutes of Health. We wish to thank John W. Melvin, Ph.D., for the use of the material testing facilities of the University of Michigan's Highway Safety Research Institute.

\section{REFERENCES}

Currey, J. D. (1969) The mechanical consequences of variation in the mineral content of bone. J. Biomech. 2, 1-11.

Dalen, J., Hellstrom, L. and Jacobson, B. (1976) Bone mineral content and mechanical strength of the femoral neck. Acta. orthop. Scand. 47, 503-508.

Fianu, S. (1976) Fetal mortality and morbidity following breech delivery. Acta obstet. gynecol. Scand. Suppl. 56.

Glenting, P. (1970) Etiology of Congenital Spastic Cerebral Palsy F.A.D.L.s Forlag, Copenhagen. 
Hubbard, R. P. (1971) Flexure of layered craniel bone. $J$. Biomech. 4, 251-263.

Mather, B. S. (1968) The effect of variation in specific gravity and ash content on the mechanical properties of human compact bone. J. Biomech. 1, 207-210.

McPherson, G. K. and Kriewall, T. J. (1980) The elastic modulus of fetal cranial bone. J. Biomech. 13, 9-16.
Wall, J. C., Chatterji, S. and Jeffery, J. W. (1972) Human femoral cortical bone: a preliminary report on the relationship between strength and density. Med. biol. Engng 10, 673-676.

Wright, T. M. and Hayes, W. C. (1976) Tensile testing of bone over a wide range of strain rates: effects of strain rate, microstructure and density. Med. biol. Engng 14, 671-679. 